\title{
Frictional behavior of synthetic gouge-bearing faults under the operation of pressure solution
}

\author{
Kyuichi Kanagawa \\ Department of Earth Sciences, Chiba University, Chiba 263-8522, Japan \\ (Received December 27, 2001; Revised June 28, 2002; Accepted July 28, 2002)
}

\begin{abstract}
Two recent experimental studies on the frictional behavior of synthetic gouge-bearing faults under the operation of pressure solution are compared. One is triaxial shear experiments on quartz gouge at high pressure-temperature hydrothermal conditions (Kanagawa et al., 2000), and the other is rotary shear experiments on halite gouge at atmospheric pressure and room temperature in the presence of methanol-water mixtures (Bos et al., 2000). In spite of quite different experimental settings and conditions, the results of these two series of experiments are strikingly similar; both cataclasis and pressure solution being active during the experiments, gouge strength rate-controlled by cataclasis, two different frictional behaviors of slip hardening and softening, slip hardening associated with gouge compaction, distributed deformation and wall-rock failure, slip softening associated with localized slip along the gouge-wall-rock interface, and the transition from slip-hardening to slip-softening behavior according to decreasing rate of pressure solution. Although there is a difference in velocity dependence of strength between quartz and halite gouges, these similarities clearly demonstrate the important effects of pressure solution on the frictional behavior of gouge-bearing faults.
\end{abstract}

\section{Introduction}

Seismogenic faulting in the continental crust mostly occurs at depths of 5-20 km at lithostatic pressures of 100-400 $\mathrm{MPa}$ and temperatures of $100-350^{\circ} \mathrm{C}$ (Sibson, 1983; Scholz, 1990). Under these pressure-temperature conditions and in the presence of water, pressure solution is likely to be an important deformation mechanism (McClay, 1977; Rutter, 1983). The important role of pressure solution in crustal faulting is indicated by widespread occurrence of quartz veins and slickenfibers in exhumed fault zones (e.g. Durney and Ramsay, 1973; Cox et al., 1991; Boullier and Robert, 1992; Cox, 1995; Hickman et al., 1995). The effects of pressure solution on the frictional behavior of faults must therefore be properly evaluated in order to achieve a more realistic understanding of strength and stability of seismogenic faults.

Two different experimental studies have recently investigated the effects of pressure solution on the frictional behavior of synthetic gouge-bearing faults. Kanagawa et al. (2000) have conducted triaxial shear experiments on synthetic quartz gouge at a temperature of $927^{\circ} \mathrm{C}$ and a pressure of $300 \mathrm{MPa}$ in the presence of water, while Bos et al. (2000) have conducted rotary shear experiments on synthetic halite gouge at room temperature and atmospheric pressure in the presence of methanol-water mixtures. In these studies, the rate of pressure solution was varied either by gouge grain size or displacement rate (Kanagawa et al., 2000), or by pore fluid composition (Bos et al., 2000). Both studies revealed strikingly similar effects of pressure solution on the frictional behavior of synthetic gouge-bearing faults. In this

Copy right (C) The Society of Geomagnetism and Earth, Planetary and Space Sciences (SGEPSS); The Seismological Society of Japan; The Volcanological Society of Japan; The Geodetic Society of Japan; The Japanese Society for Planetary Sciences. paper, I first summarize experimental results on quartz and halite gouges, then discuss their similarities and differences as well as their common implications for the frictional behavior of natural gouge-bearing faults under the operation of pressure solution.

\section{Quartz Gouge Experiments}

Kanagawa et al. (2000) have conducted shear experiments of $\approx 1 \mathrm{~mm}$ thick layer of quartz gouge sandwiched by a pair of sawcut wall-rock cylinders of porous quartz sandstone using a gas-medium triaxial testing apparatus (Paterson, 1990) at a temperature of $927^{\circ} \mathrm{C}$, a confining pressure of $300 \mathrm{MPa}$, a pore water pressure of $200 \mathrm{MPa}$, and nominally constant axial displacement rates $V$ of $0.13-6.68 \mu \mathrm{m} / \mathrm{s}$. They used two types of angular, natural quartz powder to simulate fine and coarse gouges. Approximately $98 \%$ of each is smaller than $5 \mu \mathrm{m}$ and $250 \mu \mathrm{m}$ in diameter, respectively, and their average (by weight) grain sizes are $\approx 2 \mu \mathrm{m}$ and $\approx 45 \mu \mathrm{m}$, respectively.

Two different types of frictional behavior, which are dependent on gouge grain size and displacement rate, were observed. Fine gouge at $V \approx 0.6 \mu \mathrm{m} / \mathrm{s}$ and coarse gouge at $V=0.13-0.35 \mu \mathrm{m} / \mathrm{s}$ exhibited continuous slip hardening with increasing displacement, so that coefficients of friction reach to 0.7 (Fig. 1(a)). A gradual stress drop at the end of an experiment (\#3946; Fig. 1(a)) was due to failure of the wall-rock sandstone. The slightly higher strength of coarse gouge at $V=0.35 \mu \mathrm{m} / \mathrm{s}$ ( \#3951) than that at $V=0.13 \mu \mathrm{m} / \mathrm{s}$ (\#3950) (Fig. 1(a)) indicates a positive velocity dependence of strength during slip hardening. Gouges are strongly compacted and very cohesive after experiments. Deformation is distributed across the whole gouge layer (Fig. 2(a)), and in- 
(a) Fine gouge and/or slow $v$



(b) Coarse gouge and fast $V$

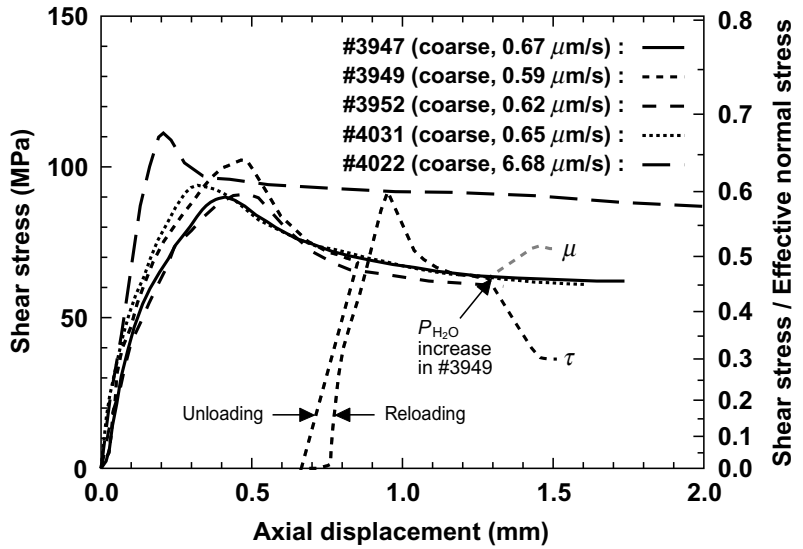

Fig. 1. Slip-hardening (a) and slip-softening (b) behaviors of quartz gouge sheared at $927^{\circ} \mathrm{C}, 300 \mathrm{MPa}$ confining pressure and $200 \mathrm{MPa}$ pore water pressure (Kanagawa et al., 2000). Shear stress along the gouge layer (left-side ordinate) and coefficient of friction (right-side ordinate) are plotted as a function of axial displacement. Fine: fine gouge $(\leq 5 \mu \mathrm{m})$, coarse: coarse gouge $(\leq 250 \mu \mathrm{m})$, and $t_{\mathrm{HIP}}$ : duration time of hot isostatic pressing before loading. Axial displacement rates are shown in $\mu \mathrm{m} / \mathrm{s}$. After increasing pore pressure in \#3949 at a point indicated by an arrow in (b), coefficient of friction is plotted by a gray dashed curve $(\mu)$, while shear stress $(\tau)$ is plotted as the same as before pore pressure increase.

volves cataclastic processes such as intergranular cracking and slip along $R_{1}$ Riedel shears (Fig. 2(a)), as well as compaction accommodated by pressure solution as illustrated by grain interlocking (Fig. 2(b)), grain interpenetration and dissolution pits (Fig. 2(c)).

In contrast, coarse gouge at $V \geq 0.6 \mu \mathrm{m} / \mathrm{s}$ exhibited a distinct peak stress followed by slip softening and subsequent quasi-stable sliding with coefficients of friction as low as 0.45 (Fig. 1(b)). The shear strength during quasistable sliding is higher at $V=6.68 \mu \mathrm{m} / \mathrm{s}$ than at $V \approx 0.6$ $\mu \mathrm{m} / \mathrm{s}$ (Fig. 1(b)), indicating a positive velocity dependence of strength. The reduced shear strength after an increase in pore water pressure at the end of an experiment (\#3949) (Fig. 1(b)) indicates a dependence of strength on effective pressure. Slip softening is associated with slip localization along the upper gouge-wall-rock interface (Fig. 2(d)) Cataclastic deformation and grain size reduction are observed adjacent to the slip surface (Fig. 2(d)). The operation of pressure solution is evident on slip surfaces as well as within the gouge layer as illustrated by euhedral grain growth (Fig. 2(e)), grain interpenetration and dissolution pits (Fig. 2(f))

\section{Halite Gouge Experiments}

Bos et al. (2000) have conducted shear experiments of $\approx 1 \mathrm{~mm}$ thick layer of halite gouge sandwiched by a pair of halite wall-rock rings using a rotary shear apparatus at room temperature, atmospheric pressure, normal stresses of $0.5-3 \mathrm{MPa}$, and sliding velocities $V$ of $0.01-5 \mu \mathrm{m} / \mathrm{s}$, in the presence of methanol-water mixtures with water content $X$ of $0-100 \%$. Samples were first sheared at dry conditions to $\approx 5 \mathrm{~mm}$ displacement, and subsequently sheared under wet conditions without interrupting experiments. Pore fluid pressure was kept at atmospheric pressure. Stepping of either $V$ or normal stress was also performed at the end of experiments. They used granular halite gouge with initial average grain sizes of normally $\approx 100 \mu \mathrm{m}$, and additionally $\approx 50 \mu \mathrm{m}$ and $\approx 200 \mu \mathrm{m}$.
Halite gouge exhibited a distinct peak stress upon adding water-bearing pore fluid, followed by two different types of frictional behavior dependent on pore fluid water content $X$ (Fig. 3(a)). Halite gouge with $X>35 \%$ exhibited quasi-stable sliding accompanied by gradual slip hardening with increasing displacement (Fig. 3(a)). Gouges and gouge-wall-rock interfaces are cohesive after experiments, but the wall rock had failed. Cataclastic deformation is indicated by grain size reduction and slip along $R_{1}$ Riedel shears (Fig. 4(a)), while the operation of pressure solution is evident from microstructures such as grain interpenetration and overgrowth (Fig. 4(b)).

In contrast, halite gouge with $X=10 \%$ exhibited pronounced slip softening with regular stick slip (Fig. 3(a)). Slip softening is associated with localized slip along the upper gouge-wall-rock interface (Fig. 4(c)). Grain size reduction is observed adjacent to the slip surface (Fig. 4(c)). The gouge layer itself is a compact aggregate with rounded grains and few cracks. Halite gouge with $X=35 \%$ exhibited transitional behavior, with stable sliding at $V=1 \mu \mathrm{m} / \mathrm{s}$ but with stick slip occurring at $V=5 \mu \mathrm{m} / \mathrm{s}$.

A clear linear relationship between shear stress and normal stress was established for all experiments (Fig. 5(a)). The coefficient of friction (line slope in Fig. 5(a)) increases with increasing pore fluid water content $X$ from $\approx 0.25$ for $X=0 \%$, through $\approx 0.5$ for $X=10 \%$ and $\approx 0.7$ for $X=$ $35 \%$, to $0.8-1$ for $X=65-100 \%$ (Fig. 5(a)). Slip-hardened gouge exhibited no clear velocity dependence of strength, while slip-softened gouge exhibited a weak negative velocity dependence (Fig. 5(b)). Halite gouge also showed no systematic grain-size dependence of strength (Fig. 3(b)).

\section{Discussion}

4.1 Comparison of quartz and halite gouge experiments

The rate of pressure solution was varied in different ways in the above two series of experiments. Kanagawa et al. (2000) tested two different gouge grain sizes and displacement rates ranging over one and a half orders of magni- 


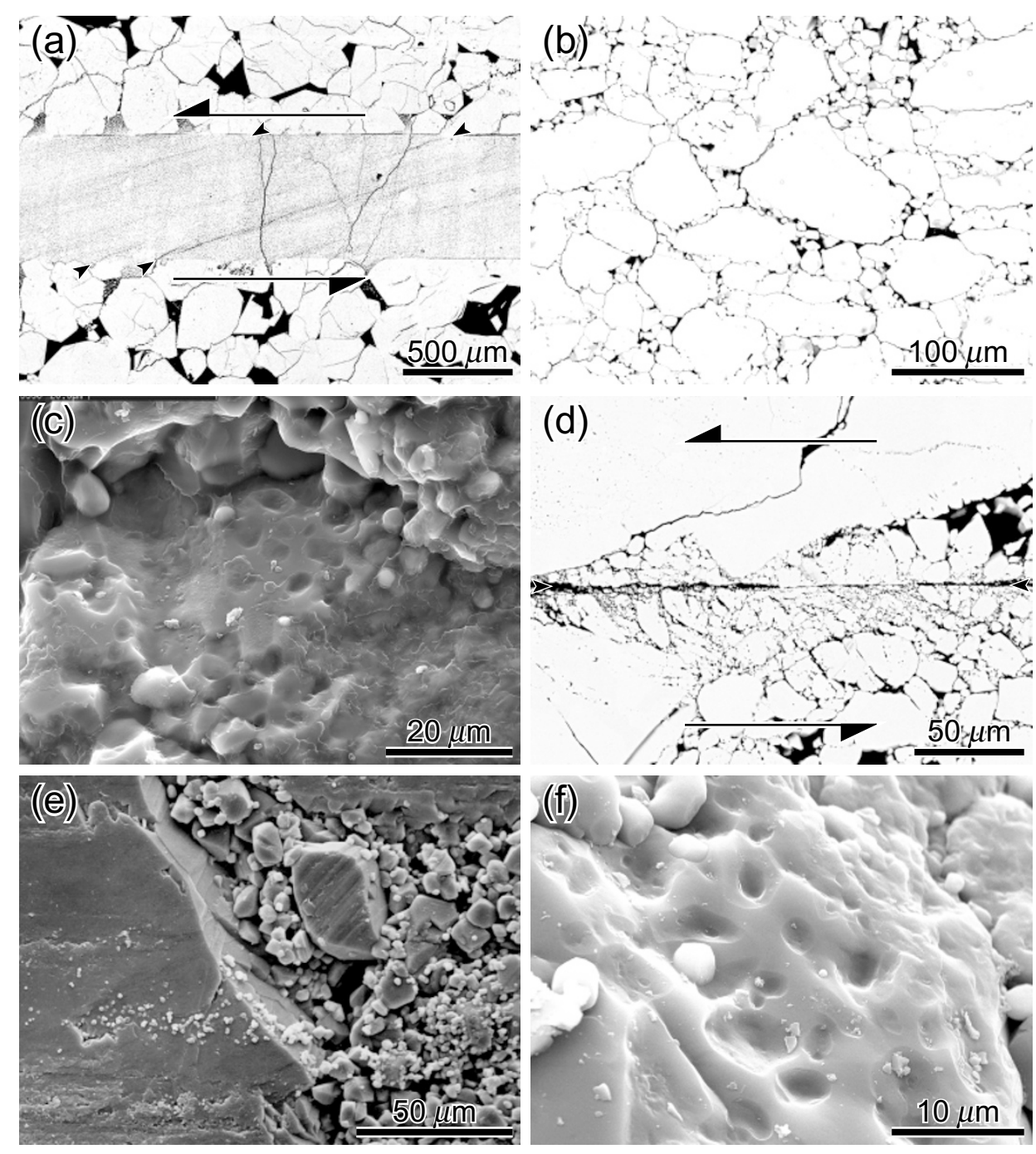

Fig. 2. Microstructures of quartz gouge sheared at $927^{\circ} \mathrm{C}, 300 \mathrm{MPa}$ confining pressure and $200 \mathrm{MPa}$ pore water pressure (Kanagawa et al., 2000). (a), (b) and (d) are back-scattered electron micrographs, while (c), (e) and (f) are secondary electron micrographs. Shear sense is indicated by a pair of arrows in (a) and (d). (a) Slip-hardened fine gouge (\#3946) at $V \approx 0.6 \mu \mathrm{m} / \mathrm{s} . R_{1}$ Riedel shears (arrowheads) are developed. (b) Slip-hardened coarse gouge (\#3950) at $V \approx 0.13 \mu \mathrm{m} / \mathrm{s}$. Gouge grains are significantly interlocking, and their boundaries interpenetrate. (c) Hand-cracked grain surfaces of \#3950 showing abundant pits due to grain interpenetration. Flaky appearance is due to the presence of impregnated epoxy on grain surfaces. (d) Slip-softened coarse gouge (\#4022) at $V=6.68 \mu \mathrm{m} / \mathrm{s}$. A continuous slip surface (arrowheads) is present along the upper interface between the gouge layer (lower) and wall-rock sandstone (upper). Note cataclastic deformation and grain size reduction adjacent to the slip surface. (e) Slip surface on wall-rock sandstone of slip-softened coarse gouge (\#3947) at $V \approx 0.6 \mu \mathrm{m} / \mathrm{s}$. Euhedral quartz crystals are present in a pocket on the right of a sandstone grain. (f) Hand-cracked grain surface of slip-softened coarse gouge (\#3949) at $V \approx 0.6 \mu \mathrm{m} / \mathrm{s}$, on which abundant pits due to grain interpenetration are present. Some small grains are still sitting on the pits.

tude. The rate of pressure solution increases with decreasing gouge grain size or displacement rate at a given temperature (Rutter, 1976; Raj, 1982; Spiers and Schutjens, 1990; Spiers et al., 1990; Dewers and Hajash, 1995). While Bos et al. (2000) tested five different water contents in the pore fluid of methanol-water mixtures. The solubility of halite in methanol-water mixtures increases with water contents (Baykara and Pharr, 1991), while the rate of diffusioncontrolled pressure solution increases with increasing solubility (Rutter, 1976; Pharr and Ashby, 1983; Gratier and Giguet, 1986). Increasing water contents in the pore fluid is therefore expected to increase the rate of pressure solution.

In spite of quite different experimental settings and conditions, the results of quartz and halite gouge experiments are strikingly similar in many ways. Microstructures of specimens clearly indicate that both cataclasis and pres- sure solution were active during the two series of experiments. Cataclastic microstructures include $R_{1}$ Riedel shears (Figs. 2(a) and 4(a)), continuous slip surfaces (Figs. 2(d) and $4(\mathrm{c})$ ), and grain size reduction along these shears and slip surfaces, while microstructures indicative of pressure solution include grain interpenetration (Figs. 2(b) and 4(b)), dissolution pits (Fig. 2(c) and (f)) and euhedral overgrowth (Figs. 2(e) and 4(b)). The strength of slip-hardened quartz gouge is not so sensitive to gouge grain size and displacement rate as predicted by pressure solution creep (Fig. 1(a); cf. Rutter, 1976; Raj, 1982; Spiers and Schutjens, 1990). The strength of slip-softened quartz gouge is dependent on effective pressure (Fig. 1(b)). The strength of halite gouge is also linearly dependent on normal stress (Fig. 5(a)). Thus deformations of both quartz and halite gouges were still ratecontrolled by cataclasis, in spite of clear microstructural ev- 

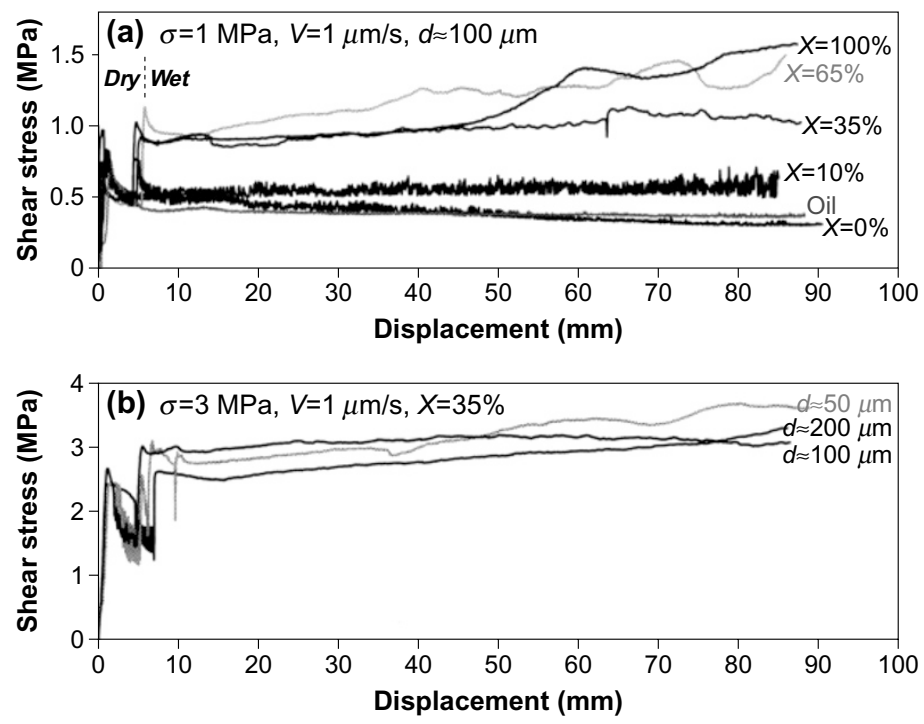

Fig. 3. Mechanical behavior of halite gouge with variable pore fluid water contents $X$ (a) and with different initial grain sizes $d$ (b) sheared at room temperature and atmospheric pressure (Bos et al., 2000). Shear stress is plotted as a function of displacement. Oil in (a) is an experiment using silicone oil as pore fluid. Normal stress is $1 \mathrm{MPa}$ in (a) and $3 \mathrm{MPa}$ in (b). Sliding velocity is $1 \mu \mathrm{m} / \mathrm{s}$ in both (a) and (b). Initial grain size in (a) is $\approx 100 \mu \mathrm{m}$, and pore fluid water content in (b) is $35 \%$.
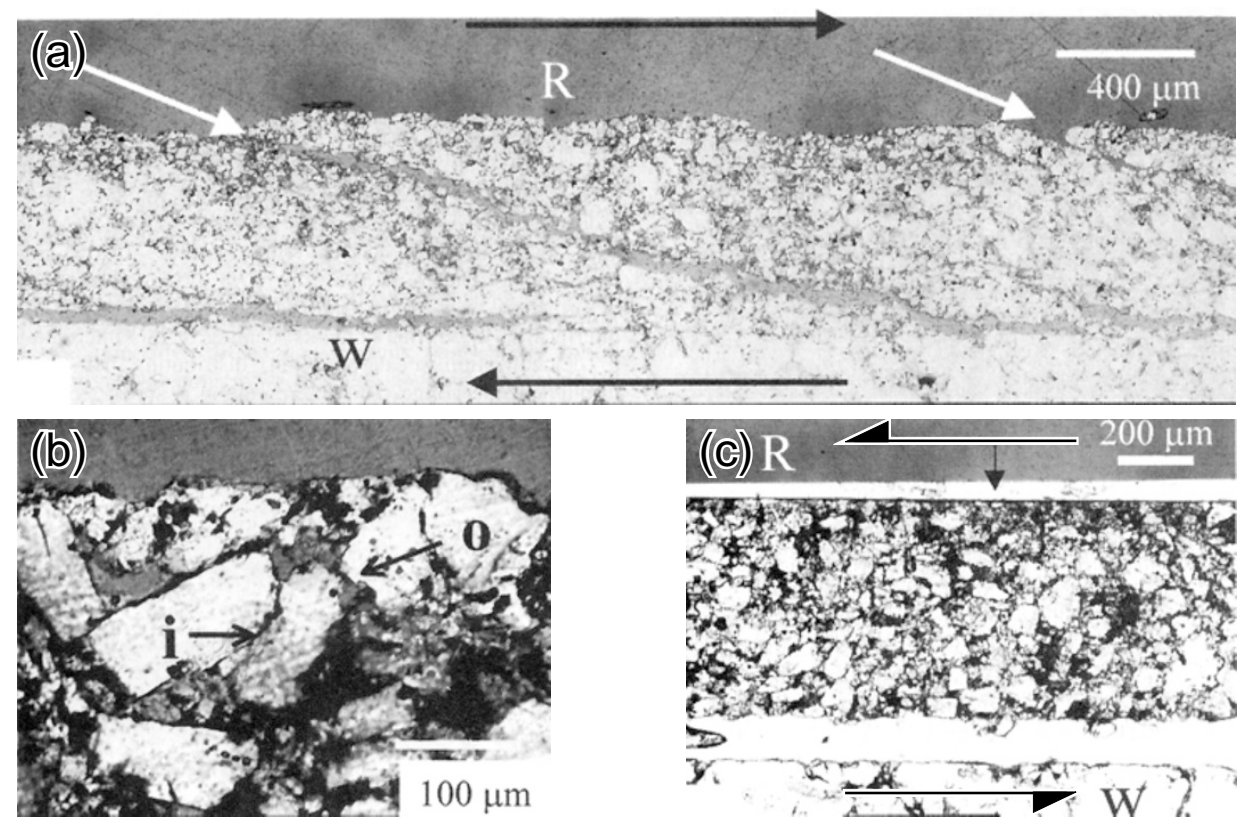

Fig. 4. Optical microstructures of halite gouge sheared at room temperature, atmospheric pressure, $1 \mathrm{MPa}$ normal stress and $1 \mu \mathrm{m} / \mathrm{s}$ sliding velocity (Bos et al., 2000). All micrographs are taken under plane-polarized light. W: wall rock material, and R: epoxy resin. (a) Slip-hardened gouge (N1) with pore fluid water contents $X=100 \%$. $R_{1}$ Riedel shears (white arrows) are developed. (b) The same gouge as (a) showing grain interpenetration $\mathbf{i}$ and overgrowth o. (c) Slip-softened gouge (N7) with $X=10 \%$. White material on the top and bottom of the gouge layer is glue. The flat top interface is a localized slip surface in this specimen.

idence for the operation of pressure solution.

Both quartz and halite gouges exhibited two different types of behavior: slip hardening and slip softening. In quartz gouge, slip hardening occurs for fine gouge or at slower displacement rates $(V \leq 0.35 \mu \mathrm{m} / \mathrm{s})$, while slip softening occurs for coarse gouge at faster displacement rates $(V \geq 0.6 \mu \mathrm{m} / \mathrm{s})($ Fig. 1). In halite gouge, stable sliding and slip hardening occur for higher pore fluid water contents $(X \geq 35 \%)$, while slip softening and stick slip occur for lower pore fluid water contents $(X \leq 35 \%)$ (Fig. 3(a)). Thus in both quartz and halite gouge experiments, pressure solution is less favored in slip-softened gouges than in sliphardened gouges. In addition in quartz gouge experiments, cataclasis is more favored for slip-softened coarse gouge than for slip-hardened fine gouge, because fracture strength of grains decreases with increasing grain size (Petch's law; cf. Scholz, 1990). The transition from slip-hardening to slipsoftening behavior therefore corresponds to decreasing rate 

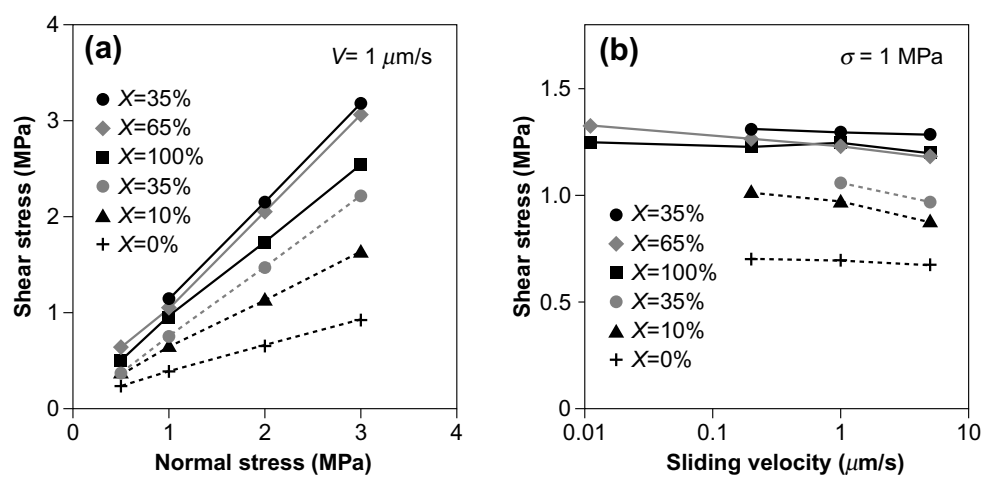

Fig. 5. (a) Shear stress plotted against normal stress (a) and sliding velocity (b) for halite gouge with variable pore fluid water contents $X$ (Bos $e t$ al., 2000). Normal-stress stepping at a sliding velocity of $1 \mu \mathrm{m} / \mathrm{s}$ (a), and sliding-velocity stepping at $1 \mathrm{MPa}$ normal stress (b) were performed after displacements of 85-90 mm shown in Fig. 3(a). Dashed lines indicate stick-slip experiments.

of pressure solution and/or increasing cataclastic deformation in both quartz and halite gouges.

Both slip-hardened quartz and halite gouges show distributed deformation throughout the gouge layer, as indicated by compaction and distributed slip along $R_{1}$ Riedel shears (Figs. 2(a) and 4(a)). Time-dependent compaction of gouge by pressure solution and resultant progressive increase in load-bearing contact area contribute to slip hardening (Kanagawa et al., 2000; Bos et al., 2000). The failure of wall rock during slip hardening of quartz and halite gouges indicates that the gouge compacted by pressure solution eventually exceeded the failure strength of wall rock in these slip-hardened experiments.

Slip-softening of both quartz and halite gouges is associated with slip localization along the upper gouge-wallrock interface (Figs. 2(d) and 4(c)). Fluid-assisted healing of the interface was not sufficient to result in its failure in the slip-softened experiments due to the lower rates of pressure solution than in the slip-hardened experiments (Bos et al., 2000). The reduced strength during interface sliding (Figs. 1(b) and 3(a)) is attributed to the much smaller loadbearing area of asperity contacts between the slip surfaces than that of grain-to-grain contacts within the gouge layer before slip softening, as well as to the role of fluid films and dissolution processes in modifying the resistance to frictional sliding (Kanagawa et al., 2000).

Although grain size is a critical factor affecting the mechanical behavior of quartz gouge, it does not apparently affect gouge strength, because no difference in strength during initial slip hardening exists between fine and coarse gouges at $V \approx 0.6 \mu \mathrm{m} / \mathrm{s}$ (Fig. 1). Halite gouge also shows no systematic grain-size dependence of strength (Fig. 3(b)).

Only a big difference between quartz and halite gouges is velocity dependence of strength. Quartz gouge exhibited a clear positive velocity dependence of strength, i.e. velocity strengthening, during both behaviors of slip hardening and slip softening (Fig. 1). Velocity strengthening is interpreted to be a response to increased cataclastic processes at faster displacement rates, fragmenting gouge grains, and thereby increasing the number of grain-to-grain or asperity contacts and the load-bearing contact area (Kanagawa et al., 2000). Interface sliding after slip softening of quartz gouge was quasi-stable, as predicted by its velocity strengthening. In contrast, halite gouge exhibited a rather neutral velocity dependence of strength in the slip-hardened experiments, and a weak negative velocity dependence of strength, i.e. velocity weakening, in the slip-softened experiments (Fig. 5(b)). Stick slip occurred during slip softening and subsequent interface sliding of halite gouge, as predicted by its velocity weakening. Stick slip is interpreted to be due to fluid-assisted healing of the gouge-wall-rock interface and its failure (Bos et al., 2000). Although no explanation is given for velocity weakening by Bos et al. (2000), it may be due to that increasing sliding velocity leads to decreasing rate of fluid-assisted healing, and thereby interface strength. The reason for the difference in velocity dependence of strength between quartz and halite gouges is unknown at present. Dissolution of fragmented grains produced by cataclastic deformation may be so fast in halite gouge that cataclastic deformation may have not affected the load-bearing grain or asperity contact area as much as in quartz gouge.

\subsection{Implications for natural gouge-bearing faults}

Although quartz gouge experiments by Kanagawa et al. (2000) and halite gouge experiments by Bos et al. (2000) are too simplified to apply their results directly to natural gougebearing faults, the strikingly similar results of these two series of experiments suggest some common implications for the frictional behavior of gouge-bearing faults under the operation of pressure solution.

The transition from slip-hardening to slip-softening behavior according to decreasing rate of thermally activated pressure solution predicts that this transition also occurs with decreasing temperature (Kanagawa et al., 2000). Along a crustal-scale, gouge-bearing fault under conditions which favor pressure solution, we can thus expect a depth where this transition occurs, which is dependent primarily on temperature, but also on displacement rate and gouge grain size. Above this transitional depth, the fault would exhibit slip softening associated with slip localization along the gougewall-rock interface, and subsequent stick slip or quasi-stable interface sliding with low strength. Fluid-assisted healing of the interface and its failure is responsible not only for stick slip (Bos et al., 2000), but may also for recurrence of earthquake faulting (Angevine et al., 1982). Slip softening itself may also represent a new variety of instability which can control rupture nucleation and recurrence independently 
on velocity dependence of strength (Kanagawa et al., 2000). Because slip during slip softening is much slower than that during stick slip (Fig. 3), the former may represent slow earthquakes. Below the transitional depth, the fault would exhibit stable sliding with high strength accompanied by slip hardening and distributed deformation, and become as strong as or even stronger than its wall rocks, while its strength is still rate-controlled by cataclasis. Earthquake faulting below this depth may not be nucleated along the fault, but by failure of wall rocks.

Acknowledgments. I thank Stephen Cox and Shuqing Zhang for their cooperation with quartz gouge experiments and discussions, Bart Bos and Chris Spiers for their kind permission to cite figures from Bos et al. (2000), and Chris Scholz and Hidemi Tanaka for their helpful reviews. Quartz gouge experiments were supported by Japan Society for the Promotion of Sciences, Research School of Earth Sciences at Australian National University, and Australian Academy of Sciences.

\section{References}

Angevine, C. L., D. L. Turcotte, and M. D. Furnish, Pressure solution lithification as a mechanism for the stick slip behavior of faults, Tectonics, 1, 151-160, 1982 .

Baykara, T. and G. M. Pharr, Effects of liquid phases on intrinsic interfacial sliding of alkali halide crystals, Acta Metall. Mater., 39, 1141-1150, 1991.

Bos, B., C. J. Peach, and C. J. Spiers, Slip behavior of simulated gougebearing faults under conditions favoring pressure solution, J. Geophys. Res., 105, 16,699-16,717, 2000.

Boullier, A.-M. and F. Robert, Paleoseismic events recorded in Archaean gold-quartz vein networks, Val d'Or, Abitibi, Quebec, Canada, J. Struct. Geol., 14, 161-179, 1992.

Cox, S. F., Faulting processes at high fluid pressures: An example of fault valve behaviour from the Wattle Gully Fault, Victoria, Australia, J. Geophys. Res., 100, 12,841-12,859, 1995.

Cox, S. F., V. J. Wall, M. A. Etheridge, and T. F. Potter, Deformational and metamorphic processes in the formation of mesothermal vein-hosted gold deposits - examples from the Lachlan Fold Belt in central Victoria, Australia, Ore Geol. Rev., 6, 391-423, 1991.

Dewers, T. and A. Hajash, Rate laws for water-assisted compaction and stress-induced water-rock interaction in sandstones, J. Geophys. Res., 100, 13,093-13,112, 1995.

Durney, D. W. and J. G. Ramsay, Incremental strains measured by syntectonic crystal growths, in Gravity and Tectonics, edited by K. A. De Jong and R. Scholten, pp. 67-96, John Wiley, New York, 1973.

Gratier, J. P. and R. Giguet, Experimental pressure solution-deposition on quartz grains: The crucial effect of the nature of the fluid, J. Struct. Geol., 8, 845-856, 1986.

Hickman, S., R. Sibson, and R. Bruhn, Introduction to special section: Mechanical involvement of fluids in faulting, J. Geophys. Res., 100, 12,831-12,840, 1995.

Kanagawa, K., S. F. Cox, and S. Zhang, Effects of dissolution-precipitation processes on the strength and mechanical behavior of quartz gouge at high-temperature hydrothermal conditions, J. Geophys. Res., 105, 11,115-11,126, 2000.

McClay, K. R., Pressure solution and Coble creep in rocks and minerals: A review, J. Geol. Soc. London, 134, 57-70, 1977.

Paterson, M. S., Rock deformation experimentation, in The Brittle-Ductile Transition in Rocks, Geophys. Monogr. Ser., 56, edited by A. G. Duba et al., pp. 187-194, AGU, Washington, D.C., 1990.

Pharr, G. M. and M. F. Ashby, On creep enhanced by a liquid phase, Acta Metall., 31, 129-138, 1983.

Raj, R., Creep in polycrystalline aggregates by matter transport through a liquid phase, J. Geophys. Res., 87, 4731-4739, 1982.

Rutter, E. H., The kinetics of rock deformation by pressure solution, Phil. Trans. R. Soc. London, Ser. A, 283, 203-219, 1976.

Rutter, E. H., Pressure solution in nature, theory and experiment, J. Geol. Soc. London, 140, 725-740, 1983.

Scholz, C. H., The Mechanics of Earthquakes and Faulting, 439 pp., Cambridge Univ. Press, New York, 1990.

Sibson, R. H., Continental fault structure and the shallow earthquake source, J. Geol. Soc. London, 140, 741-767, 1983.

Spiers, C. J. and P. M. T. M. Schutjens, Densification of crystalline aggregates by fluid-phase diffusional creep, in Deformation Processes in Minerals, Ceramics and Rocks, edited by D. J. Barber and P. G. Meredith, pp. 334-353, Unwin Hyman, London, 1990.

Spiers, C. J., P. M. T. M. Schutjens, R. H. Brezesowsky, C. J. Peach, J. L. Liezenberg, and H. J. Zwart, Experimental determination of constitutive parameters governing creep of rocksalt by pressure solution, in Deformation Mechanisms, Rheology and Tectonics, edited by R. J. Knipe and E. H. Rutter, Geol. Soc. Spec. Publ., 54, 215-227, 1990.

K. Kanagawa (e-mail: kyu@earth.s.chiba-u.ac.jp) 